\title{
Testing the social competition hypothesis of depression using a simple economic game
}

Aleksandra Kupferberg, Oliver M. Hager, Urs Fischbacher, Laura S. Brändle, Melanie Haynes and Gregor Hasler

\section{Background}

Price's social competition hypothesis interprets the depressive state as an unconscious, involuntary losing strategy, which enables individuals to yield and accept defeat in competitive situations.

\section{Aims}

We investigated whether patients who suffer from major depressive disorder (MDD) would avoid competition more often than either patients suffering from borderline personality disorder (BPD) or healthy controls.

\section{Method}

In a simple paper-folding task healthy participants and patiens with MDD and BPD were matched with two opponents, one with an unknown diagnosis and one who shared their clinical diagnosis, and they had to choose either a competitive or cooperative payment scheme for task completion.

\section{Results}

When playing against an unknown opponent, but not the opponent with the same diagnosis, the patients with depression chose the competitive payment scheme statistically less often than healthy controls and patients diagnosed with BPD.

\section{Conclusion}

The competition avoidance against the unknown opponent is consistent with Price's social competition hypothesis.

\section{Declaration of interest}

G.H. received research support, consulting fees and speaker honoraria from Lundbeck, AstraZeneca, Servier, Eli Lilly, Roche and Novartis.

\section{Copyright and usage}

(c) The Royal College of Psychiatrists 2016. This is an open access article distributed under the terms of the Creative Commons NonCommercial, No Derivatives (CC BY-NC-ND) licence.
Major depressive disorder (MDD) represents a significant and common cause of social impairment ${ }^{1}$ and is one of the leading global causes of disability-adjusted life-years. ${ }^{2}$ Even during the remission phase of the illness, patients who previously suffered from depression show impairments in psychosocial domains, ${ }^{3}$ like the inability to socialise, ${ }^{4,5}$ negative interactions with their spouse and more family conflicts. ${ }^{6-9}$ Depression limits activities of daily living at home and school, resulting in higher unemployment ${ }^{10}$ and adverse social outcomes such as reduced educational attainment, increased likelihood of teenage parenthood and marital instability. ${ }^{11-14}$ The reasons behind social impairments are not well understood, ${ }^{15}$ and the results of previous studies on social cooperation in depression applying simple economic games have been inconclusive. Although some studies have suggested that depressive symptoms relate to an uncooperative pattern of response, like making fewer altruistic responses in a trust game ${ }^{16}$ or offering lower contributions in a public goods game, ${ }^{17}$ others have shown the opposite pattern. For instance, it has been demonstrated that in the prisoner's dilemma game, patients with depression respond more cooperatively to overtures from their co-players than do controls. $^{18}$

Since depression is so commonly observed across the world, an increasing number of researchers have attempted to explain it and social impairments caused by it from the perspective of evolutionary adaptations. ${ }^{19-22}$ One of the leading theories, the social competition theory, interprets depression as an appeasement display inherited from our ancestors as a mechanism for yielding in competitive situations. ${ }^{21}$ When chances of winning in a social competition are low, the involuntary subordinate strategy prevents the individual with depression from attempting to make a comeback and inhibits aggressive behaviour towards rivals through communicating a non-combative status by displaying submissive and affiliative behaviour. Thus, although the individual gives up any chance of winning, he also reduces the damage caused by a potential loss. ${ }^{20}$ This theory is supported by clinical evidence showing that episodes of depression are precipitated by social competition and are resolved by reconciliation. ${ }^{23,24}$ Additionally, research has shown that treating submissive animals with an antidepressant significantly reduces submissive behaviour. ${ }^{25,26}$ Despite this evidence, we found no published studies that experimentally tested whether patients with depression avoid competing more than healthy individuals in the same context.

In this paper, we use an economic experiment that simulates real-life interactions in controlled settings using monetary incentives. Such economic experiments have been used not only to study economic situations but, increasingly, also to investigate people's willingness to either cooperate ${ }^{27}$ or compete. ${ }^{28}$ Specifically, our participants performed a real effort task and could choose between using a competitive or a cooperative payment scheme. This allowed us to investigate the differences in competitiveness between patients with MDD and healthy controls.

Based on the social competition hypothesis, ${ }^{20}$ we hypothesised that in a simple economic experiment, patients with MDD would avoid competitive situations significantly more often than healthy controls and patients with borderline personality disorder (BPD). To control for differences in the subjective estimations of the opponent's performance, we conducted two experiments in which participants needed to decide in favour of either cooperating with or competing against an opponent with no, or an unknown, diagnosis (Experiment I) and an opponent with the same diagnosis as the participant (Experiment II). They chose to either compete or cooperate before performing a task. To examine the emotional correlates of competitive behaviours, we established six fictitious scenarios describing different game outcomes and asked the participants at the end of the experiment to report their positive and negative emotions to these scenarios.

To test for specificity of results, we included a second control group of participants suffering from BPD. BPD is like MDD a severe psychiatric disorder with an affective component and impairments in social functioning. However, the evolutionary 
origin of BPD may be very different from that of MDD. Emotional instability and identity diffusion seem not to be related to social submission and to de-escalation of conflicts. Even BPD patients with depressive symptoms usually contribute to conflicts. Further, it has been suggested that patients with BPD may view relationships as competitive struggles rather than as collaborative ventures. $^{29,30}$

To avoid confounding effects due to gender differences in competitive behaviour, we included only female participants in our investigation. Several studies have shown that women avoided competition more than men although they did not differ in task performance. ${ }^{28,31}$ In addition, a study on emotion and competition showed that male participants exhibited more positive emotional responses during competition than female participants, whereas there was no gender difference in emotionality during cooperation. $^{32}$

\section{Method}

\section{Ethics statement}

The study was approved by the by the Kantonale Ethikkommision (KEK) Bern. Experiments were performed in agreement with this institution's statement (Reference number: 260/09), according to Swiss law and institutional guidelines.

\section{Participants}

We administered the experimental tasks to 36 healthy controls, 24 patients with MDD and 17 patients with BPD (Table 1). All participants were female. The two patient groups and healthy controls were matched for education level (Table 1). Patients with MDD and healthy controls were also matched for age. The patients were Swiss residents and were recruited from the University Hospital of Psychiatry Bern. The healthy controls were also Swiss residents and were recruited either from the administration department of the University Hospital of Psychiatry Bern or through newspaper ads or public advertisement sheets placed in surrounding locations.
Participants in the depressed group met DSM-IV Axis I and II criteria for current (single or recurrent) MDD with a minimum Beck Depression Inventory (BDI) score ${ }^{33}$ of 14 (mean score: 26; Table 1). The exclusion criteria for the MDD group included significant medical or neurological disorders, head injuries, firstdegree family history of psychoses, dementia, current substance abuse or substance dependency and clinical instability (i.e. acute risk for self-harm, or suicidal or violent behaviour). For the BPD group, exclusion criteria were identical with the exception of current MDD diagnosis, but not depressive symptoms. The exclusion criteria for the control participants encompassed current or past Axis I or Axis II disorders or any Axis I disorder in a firstdegree relative. Detailed medical records of all participants were assessed. All participants gave written informed consent and were paid for participation.

In the MDD group, 20 from 24 patients were taking at least one antidepressant, 9 an antipsychotic, 1 an antiepileptic drug and 3 patients took lithium. In the BPD group, 10 from 17 patients were taking an antidepressant, 6 an antipsychotic, 5 an antiepileptic and 2 were on lithium (see Data supplement for more detail on psychotropic medication of the participants).

\section{Clinical assessment}

In addition to the Structured Clinical Interview for the DSM-IV $(\mathrm{SCID})^{34}$ and BDI measures, all participants completed the Beck Anxiety Inventory (BAI), ${ }^{35}$ the Montgomery-Asberg Depression Rating Scale (MADRS); ${ }^{36}$ the Global Assessment of Functioning scale (GAF); ${ }^{34}$ the Zanarini Rating Scale for Borderline Personality Disorder (ZAN-BPD); ${ }^{37}$ a questionnaire on socio-demographic characteristics; and a questionnaire about nicotine/alcohol consumption. Further, we assessed experienced social support using the 14-item Questionnaire on Social Support (F-SozU K-14). ${ }^{38}$ This questionnaire measures how social support (including emotional support, practical support and social integration) from the social network is perceived by the participant. Higher values indicate higher perceived social support. The participants additionally reported information about weight, height and physical disturbances. The study was approved by the regional ethics

\begin{tabular}{|c|c|c|c|c|}
\hline & Healthy controls & MDD & BPD & Statistics \\
\hline Participants, $n$ & 36 & 24 & 17 & \\
\hline Age, years: mean (s.d.) & $36.9(11.9)$ & $43.6(14.0)$ & $30.5(11.1)$ & $F(2,74)=5.59 ; P<0.05^{a}$ \\
\hline Education-level match, mean (s.d.) & $5(1.9)$ & $4.2(1.6)$ & $4.1(1.3)$ & $F(2,74)=2.75 ; P=0.07$ \\
\hline ZAN-BPD, mean (s.d.) & $0.6(0.2)$ & $2.3(3.0)$ & $10.9(5.9)$ & $F(2,74)=65.8 ; P<0.001^{b}$ \\
\hline BDI, mean (s.d.) & $1.5(2.5)$ & $23.1(11.9)$ & $17.9(12.7)$ & $F(2,74)=48.9 ; P<0.001^{c}$ \\
\hline BAl, mean (s.d.) & $2(2.1)$ & $20.3(12.7)$ & $14.2(9.9)$ & $F(2,74)=35.01 ; P<0.001^{d}$ \\
\hline MADRS, mean (s.d.) & $0.3(0.6)$ & $22(8.3)$ & $13.1(9.9)$ & $F(2,74)=80.8 ; P<0.001^{e}$ \\
\hline GAF, mean (s.d.) & $88.6(2.5)$ & $55.1(12.6)$ & $57.5(3.1)$ & $F(2,74)=115.2 ; P<0.001^{\dagger}$ \\
\hline BMI, mean (s.d.) & $22.7(3.5)$ & $25.7(7.9)$ & $26.2(6.8)$ & $F(2,74)=2.78 ; P=0.07$ \\
\hline F-SozU, mean (s.d.) & $4.5(0.5)$ & $3.8(0.7)$ & $3.6(0.8)$ & $F(2,74)=12.84 ; P<0.001^{g}$ \\
\hline \multicolumn{5}{|c|}{ 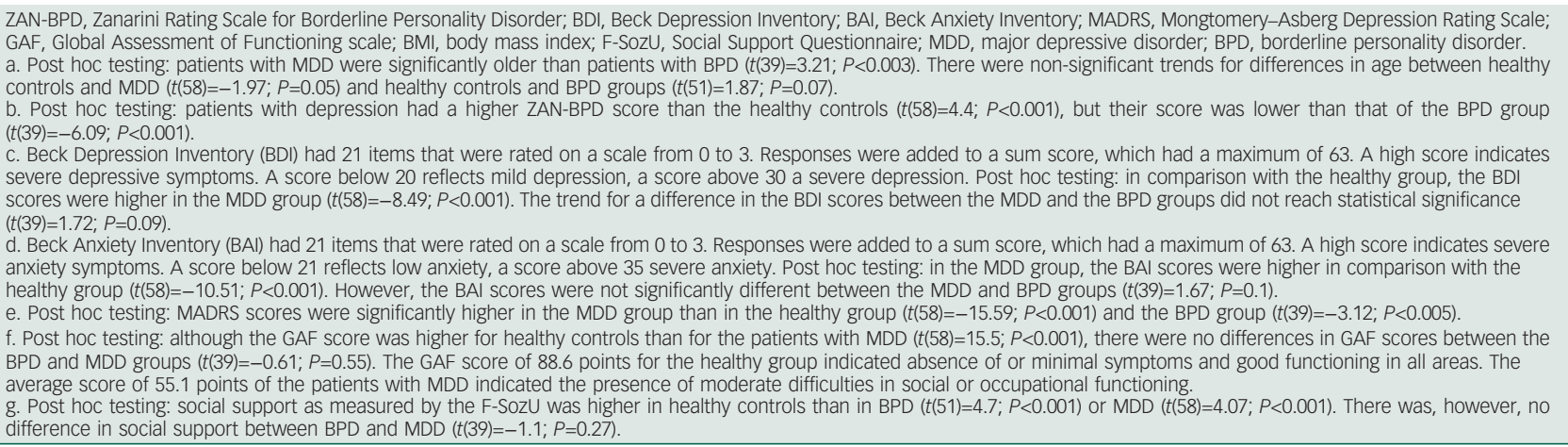 } \\
\hline
\end{tabular}


committee (Kantonale Ethikkomission Bern) and was conducted in accordance with the Declaration of Helsinki.

\section{Procedure}

The investigation reported here was part of a larger project with a series of experiments in which several aspects of social behaviour (risk, trust and punishment) were investigated using different experimental tasks. In our study, each participant was matched with an opponent and could make the decision to choose between a cooperative and a competitive payment scheme before performing the actual task.

Once the participant chose her scheme, she performed a real task. We decided to use a simple motor paper-folding task which did not require complex cognitive resources. The task involved folding as many DIN-A4 papers as possible and then inserting them into DIN-C5 envelopes within a 5-min period. For every packed envelope, the participants received 1 monetary unit. If the participant chose the cooperative payment scheme, she received the average amount of all monetary units gained by both players. If she chose the competitive payment scheme, her performance was compared with the opponent's performance. The participant received 0 monetary unit if she packed fewer envelopes than her opponent, and received all monetary units gained by both players plus an additional $50 \%$ of the total amount if she packed more envelopes than her opponent. At the end of the experiment, all monetary units were converted into Swiss Francs (1 monetary unit=0.2 CHF) and reimbursed, together with a show-up fee.

Before making the decision, the participants were informed about their opponent's status. The opponent could either be healthy or have an unknown medical or psychiatric condition (Experiment I), or could have the same psychiatric diagnosis as the participant (Experiment II). Thus, in Experiment II, healthy control participants were matched with healthy opponents, patients with MDD with an opponent suffering from MDD and patients with BPD with fellow patients with BPD. The two experiments were presented in a random order.

To assess the emotional responses to all possible outcomes of the cooperative and competitive situations, we used six fictitious scenarios at the end of the experiment (see Table 2 and a detailed description in the Data supplement). These scenarios included winning a competition against unknown and same opponents, losing competition against unknown and same opponents and cooperation against an unknown opponent with the outcome of folding either more or less envelopes than the opponent. The participants were asked to imagine themselves in each of these scenarios and indicate their experienced emotions on an adapted version of the Positive and Negative Affect Schedule (PANAS) from Watson et al. ${ }^{39}$

\section{Statistical analysis}

IBM SPSS Statistics 20 was used for all analyses. For clinical data analysis, we ran an analysis of variance (ANOVA) with age, education, BDI scores, BAI scores, MADRS scores, BMI scores, F-SozU scores and GAF scores as the dependent variables and participant group (healthy, BPD or MDD) as the independent variable.

A Pearson's chi-squared test was used to determine whether participants' competitiveness (choice of the competition or cooperation payoff scheme) depended on (a) participants' mental status (MDD, BPD or healthy) and (b) the diagnosis of the opponent (same/unknown or no diagnosis). We first tested the difference in competitive preferences between the patients with MDD and healthy participants by performing two Pearson's chi-squared tests using the variables payoff scheme and opponent diagnosis for the match with the unknown opponent (Experiment I) and the second test for the match with the opponent who had the same mental status (Experiment II). Two additional chi-squared tests were conducted to test the difference in competitive preferences for both opponent types between the MDD and BPD groups.

In every participant group, we used $t$-tests to examine whether opponent type (same/unknown or no diagnosis) biased the participant's decision to cooperate or not.

To test for the difference in the performance of the paperfolding task, we conducted an ANOVA on the number of packed envelopes across the MDD, healthy and BPD groups as well as a more powerful $t$-test between the MDD and the healthy groups.

We further analysed whether the task performance depends on the participants' competitive preferences. To this end, we conducted a $t$-test to compare the outcomes of the competitors and the cooperators in every participant group and across all participants, for both matching with an opponent with the same diagnosis or one having an unknown diagnosis.

To investigate whether depressive symptoms correlated with the competitive behaviours of the patients with MDD, we conducted independent paired samples $t$-tests on the BDI, BAI and MADRS scores between those participants who chose cooperation (cooperators) and those who chose competition (competitors) when matched with both the opponent with the same diagnosis and the opponent with an unknown, or no, diagnosis.

\section{Results}

\section{Demographic and clinical characteristics}

We included 24 patients with MDD, 17 patients with BPD and 36 healthy controls (all female). Table 1 shows the sample's clinical characteristics. Education level was measured using a rating scale ranging from 0 (no school finished) to 9 (high university degree). From the healthy group, 22 participants were single, 11 married and 3 divorced. From the depressed group, 10 were single, 4 married, 9 divorced and 1 was a widow. From the BPD group, 13 were single, 2 married and 2 divorced. Further, $83 \%$ of healthy participants, $50 \%$ of patients with depression and $47 \%$ of patients with BPD were employed, at least partly. As a result of our matching, the MDD and healthy control groups did not differ significantly in either age or education. All three groups did not

Table 2 Clinical scores and negative affect scores for the patients with MDD

\begin{tabular}{|c|c|c|c|c|c|c|}
\hline & \multicolumn{3}{|c|}{ Same opponent } & \multicolumn{3}{|c|}{ Unknown opponent } \\
\hline & Competitors & Cooperators & $t$-test & Competitors & Cooperators & $t$-test \\
\hline BDI, mean (s.d.) & $23.4(2.4)$ & $33.9(3.1)$ & $t(22)=2.47 ; P<0.05$ & $24.8(2)$ & $38(6.8)$ & $t(22)=2.21 ; P<0.05$ \\
\hline BAl, mean (s.d.) & $17.1(2.4)$ & $28.3(6.1)$ & $t(22)=-2.11 ; P<0.05$ & $17.05(1.9)$ & $43.3(7.5)$ & $t(22)=4.61 ; P<0.001$ \\
\hline MADRS, mean (s.d.) & $19.6(1.4)$ & $27.9(4.1)$ & $t(22)=-2.43 ; P<0.05$ & $21.5(1.7)$ & $25.6(7.3)$ & $t(22)=-0.81 ; P=0.43$ \\
\hline GAF, mean (s.d.) & $59.3(2.3)$ & $44.7(4.9)$ & $t(22)=2.99 ; P<0.01$ & $55.5(2.9)$ & $52(6.1)$ & $t(22)=-0.4 ; P=0.69$ \\
\hline Negative affect, mean (s.d.) & $3.7(2.1)$ & $4.5(7.5)$ & $t(22)=-1.45 ; P=0.16$ & $6.1(6)$ & $2.3(2.7)$ & $t(22)=-2.49 ; P<0.05^{\star}$ \\
\hline
\end{tabular}


differ regarding trust and non-social risk taking as determined by simple economic games (see Data supplement for details).

\section{Competitive behaviour}

When the patients with depression were matched with an opponent with an unknown or no diagnosis, only $13 \%$ of them decided to be competitive (see Fig. 1 for the payment scheme preferences for the three participant groups). However, more than half of the participants in the healthy group (53\%) decided to compete, leading to a significant difference in choice behaviour $\left(\chi^{2}(1,60)=10.1 ; P<0.005\right)$ (Fig. 1a).

In comparison with the BPD group, in which $41 \%$ of the patients chose to compete, the patients with depression avoided competition more often $\left(\chi^{2}(1,41)=4.44 ; P<0.05\right)$ (Fig. 1a). Interestingly, the patients with MDD who chose cooperation (cooperators) indicated significantly more depressive $(t(22)=2.21$ $P<0.05)$ and anxiety symptoms $(t(22)=4.61 ; P<0.001)$ than those who chose competition (competitors, Table 2). Within patients with MDD, antidepressants as estimated by imipramine equivalents were negatively associated with competition avoidance $(t(22)$ $=-2.29 ; P<0.05)$; other psychotropic medications were not associated with participants' decisions (see Data supplement).

The choice of payment scheme considerably differed when patients with depression were informed that their opponent also suffered from MDD. In this case, $70 \%$ of the patients with depression decided to compete, in contrast to $33 \%$ of the healthy individuals who were matched with another healthy person $\left(\chi^{2}(1,60)=8.11 ; P<0.005\right)$ (Fig. 1b). However, there were no differences in competitive behaviours between the MDD and BPD groups, in which about $70 \%$ of the patients decided to compete with their opponents who had the same diagnosis $\left(\chi^{2}\right.$ $(1,41)=0 ; P=0.98)$.

Type of opponent (unknown $v$. same diagnosis) had a significant effect on the cooperation/competition decisions of patients with $\operatorname{MDD}(t(23)=4.37 ; P<0.001)$, whereas its influence on decisions did not reach statistical significance in healthy controls $(t(35)=-1.75 ; P=0.09)$ or in patients with BPD $(t(16)=$ $1.77 ; P=0.1)$.

\section{Task performance and competitive behaviour}

The average numbers of packed envelopes did not differ between diagnostic groups (healthy controls: 17.69; MDD: 15.25; BPD: $16.47 ;(F(2,76)=2.09 ; P=0.13))$. The direct $t$-test between the healthy and the MDD groups showed a trend, which did not reach statistical significance $(t(58)=1.96 ; P=0.06)$.

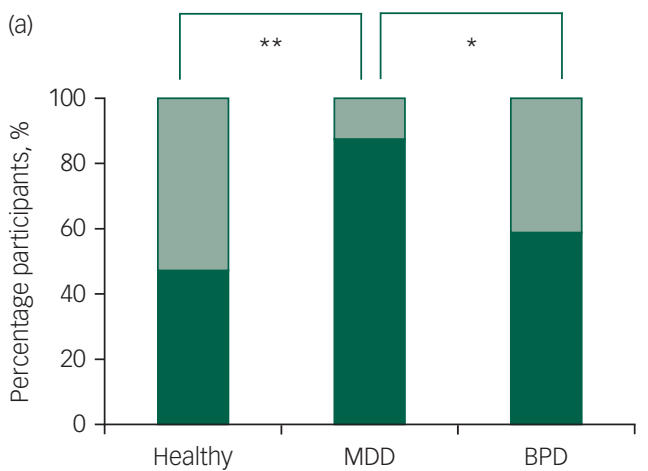

There was no correlation between the choice of payment scheme and task performance for any of the participant groups. The lowest $P$-value for the $t$-tests comparing task outcome between the competitors and the cooperators in every group, and for both opponent types, was $(t(22)=-1.88 ; P=0.07)$. However, when all three groups were included in the analysis, the competitors showed a better performance than the cooperators when matched with an unknown participant $(t(75)=-2.69 ; P<0.01)$. When matched with an opponent with the same diagnosis, this effect was not significant $(t(75)=-0.83 ; P=0.41)$.

\section{Discussion}

We investigated the competitive behaviour of patients with depression using a paradigm based on the social competition hypothesis, which is a leading theory on the social evolutionary origins of depression. ${ }^{20}$ According to this theory, MDD leads to a subordinate strategy, creating a subjective sense of incapacity and, therefore, competition avoidance. In this way, patients suffering from depression communicate to fellow human beings a noncombative status in whatever social competition situation they may find themselves in. Their depressive states enable the individuals to accept defeat in ritual agonistic encounters and prevent them from sustaining possible injuries resulting from competing with stronger individuals.

\section{Summary and interpretation of results}

Consistent with our hypothesis, when matched with an unknown opponent, patients with depression avoided competition much more often than did the healthy controls and patients with BPD, although no significant differences existed among the groups in task performance. This is consistent with the depressed people's belief that they are losing the competitions for social life necessities such as support, acceptance and care, and they commonly see this loss as being a result of their own undesirable qualities. ${ }^{40}$ However, in contrast to our hypothesis, compared with the healthy group, depressive participants chose the competition payment scheme more often than did the healthy individuals when matched with a same-diagnosis opponent. Fictitious scenarios (see Data supplement) have shown that participants who decided to compete against the unknown opponent experienced more negative emotions in the case of a fictitious loss than did those who chose cooperation, indicating that avoiding competition was not simply driven by anticipation of negative emotions. We additionally demonstrated that neither self-esteem (as indicated in the self-report) nor non-social risk preferences influenced their decisions (see Data

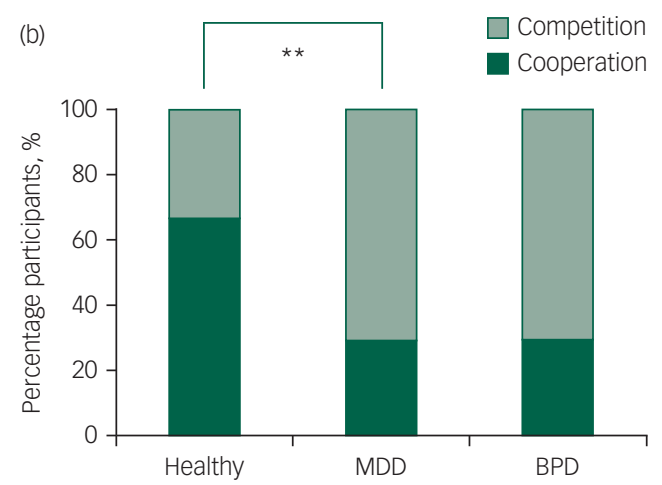

Fig. 1 Payment scheme preferences for the three participant groups. The figure on the left depicts the payment scheme preference of the healthy participants, patients with MDD and patients with BPD when matched with an opponent with an unknown diagnosis. The right figure depicts this same preference for the match with an opponent who has the same diagnosis. The light grey bars represent the percentage of participants who chose competition, and the dark grey bars represent the percentage of participants who preferred cooperation. 
supplement). However, we showed that in the MDD group, the severity of depressive and anxiety symptoms positively correlated with competition avoidance. Although the patients with BPD in the current sample also had relatively high levels of depressive symptoms, the presence of these symptoms was not associated with competition avoidance as seen in the case of MDD. The high level of depressive symptoms may reflect the recruitment of patients with BPD from in-patients settings, given that BPD is associated with persistent depressive symptoms. ${ }^{41}$ The patients with BPD in the present experiment had an average BAI-score of 14.2 (9.9), which according to the BAI-Manual ${ }^{42}$ can be evaluated as mild anxiety symptoms (ranging from 0 to 21 ). This level of anxiety symptoms is comparable with those found in other clinical studies. For example, in a psychotherapy treatment trial, the patients with BPD in two different treatment groups had an average baseline score of 18.6 (9.0) and 23.7 (11.2) respectively, ${ }^{43}$ corresponding to moderate anxiety symptoms. In another BPD psychotherapy treatment trial, both BPD treatment groups had an average score of 20.4 (3.5) and 19.3 (3.6), respectively. ${ }^{44}$ The BDI score of 17.9 (12.7) in our BPD sample indicates light depression according to the BDI manual. ${ }^{33}$ In the two studies mentioned above, the patients with BPD had more severe depressive symptoms than in our sample: 31.5 (10.7) and 37.5 (10.6), ${ }^{43}$ as well as $27.8(6.1)$ and $27.6(5.3) .{ }^{44}$ However, another study has found lower BDI scores of 12.3 (4.58) in adolescent suicide attempters suffering from BPD. ${ }^{45}$ We considered the patients with BPD with high levels of depressive symptoms as a particularly interesting control group, which would enable us to show that not all kinds of depressive symptoms relate to Price's social competition theory. Patients with BPD, even with depressive symptoms, are frequently involved in ongoing hierarchy conflicts. However, their depressive symptoms seem not to be associated with social submission and de-escalation of conflicts.

Interestingly, depressive and anxiety symptoms (as measured by the BDI and the BAI) of our participants were positively correlated with competition avoidance. These results argue for a primary, direct relationship between depressive symptoms occurring in MDD and competition avoidance, as suggested by the social competition theory. ${ }^{20}$ To evaluate the influence of emotional responses to competition, we assessed emotional affect in several fictitious game scenarios. The expected negative emotions in the case of losing seem not to be responsible for the decision against competition, since in the MDD group, competitors reported being more sensitive to losing than the cooperators. Interestingly, we have found a statistical trend for lower positive affect in the MDD group in comparison with the healthy control group in the case of fictitious winning against the opponent with the same diagnosis. This suggests a decreased positive response of the reward system, ${ }^{46}$ which might underlie a failure to maximise potential monetary earnings in patients with MDD. ${ }^{47,48}$

Contrary to our expectations, we did not see a pattern of competition avoidance when patients with depression were matched with patients having the same diagnosis. Thus, when matched with an opponent who is supposed to have similar constraints, patients with depression are more likely to choose competition. First, this indicates that the patients with MDD hold different beliefs about the relative abilities of their opponents. Second, the increased competitiveness of the patients with MDD against opponents with the same diagnosis may reflect the desires of the patients with depression to compete in situations with lower social risks. Therefore, although MDD has been associated with social competition avoidance, ${ }^{18,20}$ patients with depression might not be simply preventing competitive situations; rather, they may adjust their behaviour to the given circumstances and opponents. Thus, competitive behaviour can be modulated not only by competitiveness but also by other factors, like internal representations of the rival/opponent.

The tendency of individuals with MDD to compete against patients with a same diagnosis is in line with a recent study claiming that patients with depression have an increased desire to compete. ${ }^{40}$ Two other studies suggested that the more insecure and uncertain people feel in social relationships and in their abilities to create a positive image in the minds of others, the more competitive is their orientation to social relationships. ${ }^{49,50}$ Thus, it has been argued that competition relates to the wish to avoid the unwanted inferiority feelings associated with being rejected. ${ }^{51,52}$ Indeed, it has been shown that self-beliefs of inferiority and submissive behaviours are highly associated with depression in both clinical and non-clinical populations. ${ }^{53,54}$ Thus, competitive behaviour might serve to improve what others think about oneself and counteract the self-belief of inferiority and the belief that others also perceive one in a negative light.

In line with our finding that patients with MDD are more competitive when matched with an opponent with the same diagnosis, in their original article, Price et al stated that in depression, only hostility to higher-ranking people is inhibited, whereas hostility expressed to lower-ranking people is often increased. ${ }^{20}$ Thus, one might speculate that opponents with the same diagnosis could be perceived as lower-ranking individuals. Increased competition against opponents with the same diagnosis argues against general competition avoidance in MDD. In fact, there seems to be a complex dysregulation of competitive behaviour, which is in line with the later refinements of the social competition theory, that is, that MDD is a dysfunctioning involuntary subordinate strategy. ${ }^{21}$

Competition avoidance in patients with depression might lead to important disadvantages in the modern Western society. Competitive behaviour is ubiquitous, being present in domains as varied as business, politics, sports and intimate relationships. The romantic ${ }^{55}$ and employment marketplaces are inherently competitive; therefore, less competitive individuals are obviously at a disadvantage. The reluctance to enter competition that is necessary for many relationships at work, or in intimate relations, reduces the opportunities of patients with depression in the workplace and in romantic interpersonal relationships.

Our findings demonstrate, for the first time, experimental evidence for competition avoidance in patients with depression as proposed by the social competition theory. ${ }^{20}$ In line with this theory, our analysis showed that in comparison with healthy controls, patients with depression are less likely to choose competition when matched with an opponent with an unknown diagnosis, although there were no differences in either performance or risk preference. The negative association between competition avoidance and the dose of antidepressants in MDD is in line with animal work showing that submissive behaviour of animals who are treated with an antidepressant is significantly reduced. ${ }^{25,26}$

Our results are also in line with Hagen's bargaining model of depression, which assumes that depressive behaviour arises as a bargaining option in a situation where the individual has no other obvious means to better his or her situation and seizes the opportunity to cooperate with another 'new' individual. ${ }^{56}$ Therefore, the bargaining model and specifically the nonparticipation hypothesis predict that depressed individuals eagerly take escape routes from 'games' that they find unattractive. ${ }^{56}$ Moreover, the depressed symptoms themselves are considered such an escape route that may be used when one is cornered. However, it has to be noticed that our behavioural experiment did not allow for investigating bargaining behaviours because the participant's decision did not affect the outcome of the opponent. Further, 
the experiment was based on single decisions in the interaction with anonymous people without the option to send help signals.

\section{Strengths and limitations}

The strength of our paradigm is that it captures a situation that is well defined and close to real life because it is based on monetary incentives. The situation is also very controlled; for example, the learning of the participants' relative abilities is excluded using a one-shot game. Since lack of self-confidence of patients with depression may make them more reluctant to compete, we selected a short and simple task that both depressed and healthy individuals should be able to perform equally well. We further conducted an additional non-social experiment to separate the social from the non-social risk factors related to competition and cooperation.

This study had several methodological limitations, one being the small sample size. Since the study was conducted only with women, the results may not be generalised to men. Another limitation is that the study cannot test whether depression is a cause or an effect of low competitiveness. Although Price et al suggested that decreased competitiveness is the 'ultimate' cause of depression, it is also possible that patients with depression may attempt to increase their self-concept by competing in a field where competition is considered appropriate and encouraged. ${ }^{20}$ This aspect needs further investigation.

Although our results seem to support the social competition theory of depression, the patients with MDD might have avoided the competition because they were able to better predict their general level of ability in comparison with their opponents. Given that the decisions of patients with depression for or against competition did not affect monetary payoffs, one might speculate that these patients evaluated their relative abilities realistically, thus supporting the 'analytic rumination' hypothesis ${ }^{19,57,56}$ rather than the 'social competition' hypothesis. The analytic rumination hypothesis suggests that depression triggers focusing on one's problems and trying to analyse complex dilemmas which led to depression, which on the other hand leads to more accurate decisions. For example, a recent study has shown that when faced with the task to hire the best applicant in a simulated computerbased job search, patients with depression approximated the optimal search strategy much more closely than the nondepressed participants did. ${ }^{58}$ Although this study has a number of caveats, it seems that in specific situations depression can have a positive effect on analytical skills.

Finally, one of the limitations is that in the test condition, the patients with depression are matched with an opponent having the same diagnosis as they themselves. Thus, it would be interesting to find out whether being matched with someone with a psychiatric illness or just having a certain match is driving the results towards competition. However, that would also suggest that being paired with a healthy opponent in the case of a healthy participant should have led to higher competition, which was not the case. Nevertheless, future research should try to replicate our findings using an additional group of patients with a different psychiatric condition as a second control.

In summary, our findings show that MDD is associated with dysregulation of competitive behaviour unrelated to risk preference. Our results are in line with the evolutionary-based social competition theory ${ }^{20}$ and may have important implications for future research and patient care.

\section{Implications for therapy and future research}

Our data encourage more research on the social competition hypothesis of depression. Longitudinal investigations are needed to clarify whether competition avoidance is rather a cause or a consequence of depression, and how much it varies over time. Competition avoidance may turn out to be a helpful marker in depression to predict response to psychological and pharmacological treatments. For example, testosterone has been proved to be an antidepressant treatment. ${ }^{59-62}$ In healthy males, an increase in testosterone levels as a response to losing enhanced motivation to compete again. ${ }^{63}$ As a result, testosterone may be particularly effective in patients with depression and with pronounced competition avoidance. In children, competition avoidance might represent a marker of increased depression risk. Psychological interventions to improve motivation to compete may help to prevent the development of depression later in life. The neural substrate of competition avoidance can be measured using functional MRI. Such research will provide new insights into the pathophysiology of depression. Because Price's hypothesis is related to genetic risk, behavioural and neural measures of competition avoidance have the potential to be useful endophenotypes in MDD. ${ }^{64,65}$

Aleksandra Kupferberg, PhD, Psychiatric University Hospital, Division of Molecular Psychiatry, University of Bern, Bern, Switzerland; Oliver M. Hager, MSC, Department of Psychiatry, Psychotherapy and Psychosomatics, Psychiatric Hospital; Laboratory for Social and Neural Systems Research, Department of Economics, University of Zurich, Zurich, Switzerland; Urs Fischbacher, Prof. Dr, Department of Economics, Economics University, Konstanz, Germany; Thurgau Institute of Economics, Kreuzlingen, Switzerland; Laura S. Brändle, MSC, Melanie Haynes, DiplBiol, Gregor Hasler, MD Prof., Psychiatric University Hospital, Division of Molecular Psychiatry, University of Bern, Bern, Switzerland

Correspondence: Gregor Hasler, Psychiatric University Hospital, Division of Molecula Psychiatry, University of Bern, Bolligenstrasse 111, CH-3000 Bern 60, Switzerland. Email: gregor.hasler@puk.unibe.ch

First received 22 Jun 2015, final revision 19 Jan 2016, accepted 17 Feb 2016

\section{Funding}

This work was supported by the University of Bern.

\section{Acknowledgement}

We would like to thank Ulrich Raub for his contributions to the recruitment of study participants.

\section{References}

1 Kessler RC, Berglund P, Demler O, Jin R, Koretz D, Merikangas KR, et al. The epidemiology of major depressive disorder: results from the National Comorbidity Survey Replication (NCS-R). JAMA 2003; 289: 3095-105.

2 Mathers $C D$, Loncar D. Projections of global mortality and burden of disease from 2002 to 2030. PLOS Med 2006; 3: e442.

3 Shapira B, Zislin J, Gelfin Y, Osher Y, Gorfine M, Souery D, et al. Social adjustment and self-esteem in remitted patients with unipolar and bipolar affective disorder: a case-control study. Compr Psychiatry 1999; 40: 24-30.

4 American Psychiatric Association. Diagnostic and Statistical Manual of Mental Disorders, Fourth Edition, Text Revision: DSM-IV-TR. American Psychiatric Publishing, 2000

5 Weissman MM, Paykel ES, Siegel R, Klerman GL. The social role performance of depressed women: comparisons with a normal group. Am J Orthopsychiatry 1971; 41: $390-405$.

6 Beach SRH, Sandeen E, O'Leary KD. Depression in Marriage: A Model for Etiology and Treatment. Guilford Press, 1990

7 Hammen C, Brennan PA. Depressed adolescents of depressed and nondepressed mothers: tests of an interpersonal impairment hypothesis. J Consult Clin Psychol 2001; 69: 284-94.

8 Lewinsohn PM, Rohde P, Seeley JR. Major depressive disorder in older adolescents: prevalence, risk factors, and clinical implications. Clin Psychol Rev 1998; 18: 765-94.

9 Zlotnick C, Kohn R, Keitner G, Della Grotta SA. The relationship between quality of interpersonal relationships and major depressive disorder: findings from the National Comorbidity Survey. J Affect Disord 2000; 59: 205-15. 
10 Whooley MA, Kiefe $\mathrm{Cl}$, Chesney MA, Markovitz JH, Matthews K, Hulley SB, et al. Depressive symptoms, unemployment, and loss of income: the CARDIA study. Arch Intern Med 2002; 162: 2614-20.

11 Kessler RC, Walters EE, Forthofer MS. The social consequences of psychiatric disorders, III: probability of marital stability. Am J Psychiatry 1998; 155: 1092-6.

12 Kessler RC, Berglund PA, Foster CL, Saunders WB, Stang PE, Walters EE. Socia consequences of psychiatric disorders, II: teenage parenthood. Am J Psychiatry 1997; 154: 1405-11

13 Kessler RC, Foster CL, Saunders WB, Stang PE. Social consequences of psychiatric disorders, l: educational attainment. Am J Psychiatry 1995; 152: 1026-32.

14 Merikangas KR. Divorce and assortative mating among depressed patients. Am J Psychiatry 1984; 141: 74-6.

15 Ingram RE, Price JM. Vulnerability to Psychopathology, Second Edition: Risk Across the Lifespan. Guilford Press, 2009.

16 Zhang $H$, Sun D, Lee TMC. Impaired social decision making in patients with majo depressive disorder. Brain Behav 2012; 2: 415-23.

17 Clark C, Thorne CB, Hardy S, Cropsey KL. Cooperation and depressive symptoms. I Affect Disord 2013; 150: 1184-7.

18 McClure EB, Parrish JM, Nelson EE, Easter J, Thorne JF, Rilling JK, et al. Response to conflict and cooperation in adolescents with anxiety and mood disorders. J Abnorm Child Psychol 2007; 35: 567-77.

19 Andrews PW, Thomson JA. The bright side of being blue: depression as an adaptation for analyzing complex problems. Psychol Rev 2009; 116: 620-54.

20 Price J, Sloman L, Gardner R Jr, Gilbert P, Rohde P. The social competition hypothesis of depression. Br J Psychiatry 1994; 164: 309-15.

21 Price JS, Gardner R Jr, Erickson M. Can depression, anxiety and somatization be understood as appeasement displays? J Affect Disord 2004; 79: 1-11.

22 Sloman L. A new comprehensive evolutionary model of depression and anxiety. J Affect Disord 2008; 106: 219-28.

23 Brown GW, Harris TO, Hepworth C. Loss, humiliation and entrapment among women developing depression: a patient and non-patient comparison. Psycho Med 1995; 25: 7-21.

24 Gilbert P. Depression: The Evolution of Powerlessness. Guilford Press, 1992

25 Malatynska E, Pinhasov A, Crooke JJ, Smith-Swintosky VL, Brenneman DE. Reduction of dominant or submissive behaviors as models for antimanic or antidepressant drug testing: technical considerations. J Neurosci Methods 2007; 165: $175-82$

26 Pinhasov A, Crooke J, Rosenthal D, Brenneman D, Malatynska E. Reduction of submissive behavior model for antidepressant drug activity testing: study using a video-tracking system. Behav Pharmacol 2005; 16: 657-64.

27 Camerer $\mathrm{C}$, Fehr E. Measuring social norms and preferences using experimental games: a guide for social scientists. In Henrich J, Boyd R, Bowles S, Camerer C Fehr $\mathrm{E}$, Gintis $\mathrm{H}$ (eds) Foundations of Human Sociality: Economic Experiments and Ethnographic Evidence from Fifteen Small-Scale Societies: 55-96. Oxford University Press, 2004

28 Niederle $\mathrm{M}$, Vesterlund L. Do women shy away from competition? Do men compete too much? Q J Econ 2007; 122: 1067-101.

29 Stanley B, Siever $\sqcup$. The interpersonal dimension of borderline personality disorder: toward a neuropeptide model. Am J Psychiatry 2009; 167: 24-39.

30 Gunderson JG. Borderline Personality Disorder, Second Edition: A Clinical Guide. American Psychiatric Publishing, 2009.

31 Datta Gupta N, Poulsen A, Villeval MC. Male and Female Competitive Behavior: Experimental Evidence. Institute for the Study of Labor, 2005

32 Kivikangas JM, Kätsyri J, Järvelä S, Ravaja N. Gender differences in emotiona responses to cooperative and competitive game play. PLoS One 2014; 9: e100318.

33 Hautzinger M, Bailer M, Worrall H, Keller F. Das Beck-Depressions-Inventar (BDI). Überarbeitet und ergänzte Neuauflage. Hans Huber, 1995.

34 Wittchen $\mathrm{H}-\mathrm{U}$, Fydrich T, Zaudig M. SKID: Strukturiertes Klinisches Interview fü DSM-IV; Achse I und II. Achse II: Persönlichkeitstörungen. SKID-II. Hogrefe, Verlag für Psychologie, 1997

35 Beck AT, Steer RA, Ball R, Ranieri WF. Comparison of beck depression inventories A and II in psychiatric outpatients. J Pers Assess 1996; 67: 588-97.

36 Montgomery SA, Asberg M. A new depression scale designed to be sensitive to change. Br J Psychiatry 1979; 134: 382-9.

37 Zanarini MC, Vujanovic AA, Parachini EA, Boulanger JL, Frankenburg FR, Hennen J. Zanarini Rating Scale for Borderline Personality Disorder (ZAN-BPD): a continuous measure of DSM-IV borderline psychopathology. J Personal Disord 2003; 17 $233-42$

38 Fydrich T, Sommer G, Tydecks S, Brähler E. Fragebogen zur sozialen Unterstützung (F-SozU): Normierung der Kurzform (K-14) [Social Support Questionnaire (F-SozU): standardization of short form (K-14)]. Z Für Med Psychol 2009; 18: 43-8.

39 Watson D, Clark LA, Tellegen A. Development and validation of brief measures of positive and negative affect: the PANAS scales. J Pers Soc Psychol 1988; 54: 1063-70.

40 Gilbert $\mathrm{P}$, McEwan K, Bellew R, Mills A, Gale C. The dark side of competition: how competitive behaviour and striving to avoid inferiority are linked to depression, anxiety, stress and self-harm. Psychol Psychother Theory Res Pract 2009; 82: 123-36.

41 Skodol AE, Grilo CM, Keyes KM, Geier T, Grant BF, Hasin DS. Relationship of personality disorders to the course of major depressive disorder in a nationally representative sample. Am J Psychiatry 2011; 168: 257-64.

42 Margraf J, Beck AT, Ehlers A. Beck-Angst-Inventar: BAl; Manual. Harcourt Test Services, 2007.

43 Jørgensen CR, Freund C, Bøye R, Jordet H, Andersen D, Kjølbye M. Outcome of mentalization-based and supportive psychotherapy in patients with borderline personality disorder: a randomized trial. Acta Psychiatr Scand 2013; 127: 305-17.

44 Turner RM. Naturalistic evaluation of dialectical behavior therapy-oriented treatment for borderline personality disorder. Cogn Behav Pract 2000; 7: 413-19

45 Horesh N, Sever J, Apter A. A comparison of life events between suicidal adolescents with major depression and borderline personality disorder. Compr Psychiatry 2003; 44: 277-83.

46 Shankman SA, Nelson BD, Sarapas C, Robison-Andrew EJ, Campbell ML, Altman $\mathrm{SE}$, et al. A psychophysiological investigation of threat and reward sensitivity in individuals with panic disorder and/or major depressive disorder. I Abnorm Psychol 2013; 122: 322-38.

47 Henriques JB, Davidson RJ. Decreased responsiveness to reward in depression. Cogn Emot 2000; 14: 711-24.

48 Pizzagalli DA, Iosifescu D, Hallett LA, Ratner KG, Fava M. Reduced hedonic capacity in major depressive disorder: evidence from a probabilistic reward task. I Psychiatr Res 2008; 43: 76-87.

49 Gilbert P, Psychotherapy and Counselling for Depression. Sage, 2007.

50 Leary MR. Self Presentation: Impression Management and Interpersonal Behavior. Westview Press, 1996.

51 Dykman BM. Integrating cognitive and motivational factors in depression: initial tests of a goal-orientation approach. J Pers Soc Psychol 1998; 74: 139-58.

52 Gilbert P. Human Nature and Suffering. Lawrence Erlbaum Associates, 1992.

53 Allan S, Gilbert P. Submissive behaviour and psychopathology. Br I Clin Psychol 1997; 36: 467-88

54 Gilbert P, Allan S. The role of defeat and entrapment (arrested flight) in depression: an exploration of an evolutionary view. Psychol Med 1998; 28: 585-98.

55 Thibaut JW, Kelley HH. The Social Psychology of Groups. Wiley, 1959

56 Hagen EH. Evolutionary theories of depression: a critical review. Can J PSychiatry 2011; 56: 716-26.

57 Watson PJ, Andrews PW. Toward a revised evolutionary adaptationist analysis of depression: the social navigation hypothesis. J Affect Disord 2002; 72: 1-14.

58 Von Helversen B, Wilke A, Johnson T, Schmid G, Klapp B. Performance benefits of depression: sequential decision making in a healthy sample and a clinically depressed sample. J Abnorm Psychol 2011; 120: 962-8.

59 schmidt PJ, Daly RC, Bloch M, Smith MJ, Danaceau MA, St Clair LS, et al. Dehydroepiandrosterone monotherapy in midlife-onset major and minor depression. Arch Gen Psychiatry 2005; 62: 154-62.

60 Peixoto $C$, Devicari Cheda JN, Nardi $A E$, veras AB, Cardoso A. The effects of dehydroepiandrosterone (DHEA) in the treatment of depression and depressive symptoms in other psychiatric and medical illnesses: a systematic review. Curr Drug Targets 2014; 15: 901-14

61 Khera M. Patients with testosterone deficit syndrome and depression. Arch Esp Urol 2013; 66: 729-36.

62 Zarrouf FA, Artz S, Griffith J, Sirbu C, Kommor M. Testosterone and depression: systematic review and meta-analysis. J Psychiatr Pract 2009; 15: 289-305.

63 Mehta PH, Josephs RA. Testosterone change after losing predicts the decision to compete again. Horm Behav 2006; 50: 684-92.

64 Hasler G, Drevets WC, Manji HK, Charney DS. Discovering endophenotypes for major depression. Neuropsychopharmacology 2004; 29: 1765-81.

65 Hasler G, Northoff G. Discovering imaging endophenotypes for major depression. Mol Psychiatry 2011; 16: 604-19. 